\title{
Experiências de regulação de preços de medicamentos em países selecionados: lições para o Brasil
}

\section{Drug price regulation experiences in selected countries: lessons for Brazil}

\author{
Caroline Mirandal,* (iD) \\ Julia Paranhos' \\ Lia Hasenclever ${ }^{1,11}$ (ID
}

\begin{abstract}
RESUMO
Introdução: A regulação de preços no mercado farmacêutico é comum aos países de diversos níveis de desenvolvimento, mas a motivação para sua implementação difere entre países desenvolvidos e em desenvolvimento. Objetivo: Discutir, com base em outras experiências de regulação de preços de medicamentos em países selecionados, a regulação de preços de medicamentos em vigor no Brasil, de modo a acumular evidências da necessidade de melhorias na regulação em vigor. Método: Revisão da literatura sobre modelos regulatórios de preços de medicamentos em países selecionados. Resultados: Com a sistematização da literatura, realizou-se a análise dos diferentes tipos de regulação de preços de medicamentos por grupo de países europeus e em desenvolvimento. Conclusões: A revisão de literatura serviu para observar as diferenças da regulação de preços dos medicamentos em distintos países em comparação com a brasileira e trazer sugestões de como aperfeiçoar a regulação atual para se alcançar resultados mais desejáveis.
\end{abstract}

PALAVRAS-CHAVE: Regulamentação Governamental; Preço de Medicamento; Medicamentos Genéricos

\begin{abstract}
Introduction: Price regulation in the pharmaceutical market is common to countries at different levels of development, but the motivation for its implementation differs between developed and developing countries. Objective: To discuss the drug price regulation in Brazil and the need for improvements based on experiences and evidences of drug price regulation in selected countries. Method: Review of the literature on regulatory models of drug prices in selected countries. Results: Based on the systematized literature, an analysis of different types of drug price regulation by group (European and developing countries) was carried out. Conclusions: The literature review was used to observe the different drug price regulations among countries, and to identify examples on how to improve the current regulation in Brazil to achieve more desirable results.
\end{abstract}

KEYWORDS: Government Regulation; Drug Price; Generic Drugs
I Instituto de Economia, Universidade Federal do Rio de Janeiro, Rio de Janeiro, RJ, Brasil

" Universidade Cândido Mendes, Campos dos Goytacazes, RJ, Brasil

\footnotetext{
* E-mail: caroline.souza@pped.ie.ufrj.br
} 


\section{INTRODUÇÃO}

Em mercados onde as forças competitivas não estão presentes, pelo menos não em extensão suficiente para garantir preços eficientes, como nos mercados farmacêuticos, há amplo consenso de que é necessária alguma forma de intervenção por parte do Estado, seja para promover a concorrência ou para regular os preços dos medicamentos ${ }^{1}$.

A regulação de preços no mercado farmacêutico é comum aos países de diversos níveis de desenvolvimento, mas a motivação para sua implementação difere entre países desenvolvidos e países em desenvolvimento (PED). Nos países em que uma porção substancial da população é coberta por esquemas de seguro saúde, controles de preços são vistos como parte da estratégia de contenção de gastos. Em países em que os consumidores arcam com a maior parte das despesas com medicamentos, o controle de preços é visto principalmente como um modo de aumentar o acesso².

Esta regulação pode ocorrer por meio de duas óticas: (i) a da oferta, que pode atuar de duas formas, minorando os problemas decorrentes do funcionamento do mercado (efeitos indiretos sobre os preços) ou por meio de políticas ativas sobre preços e/ou margens de lucro (efeitos diretos na redução dos preços); e (ii) a da demanda, buscando fortalecer o poder de barganha do comprador ${ }^{2}$.

Como apontam Espin et al. ${ }^{1}$, o alto preço dos medicamentos é uma grande preocupação para governos, formuladores de políticas, seguradoras e pacientes, dado que podem tornar os medicamentos inacessíveis, comprometer o acesso equitativo e ameaçar a sustentabilidade financeira dos sistemas públicos de saúde. Segundo Sood et al. ${ }^{3}$, regulações tendem a restringir os gastos com medicamentos, melhorando o bem-estar da população, mas, se inadequadas, também podem limitar os incentivos à pesquisa e desenvolvimento (P\&D), atrasar o lançamento, limitar a disponibilidade e até mesmo a concorrência de novos medicamentos.

$\mathrm{Na}$ onda de desregulamentação que foi imposta aos PED entre 1980-1990, o Brasil desregulamentou amplamente os preços dos produtos farmacêuticos. Antes disso, os preços dos medicamentos eram estritamente regulados pelo Comitê Interministerial de Preços (CIP), que monitorava os preços de vários produtos, incluindo medicamentos e outros produtos relacionados à saúde ${ }^{4}$. Além disso, a Central de Medicamentos (Ceme), órgão da Presidência da República, destinado a promover e organizar o fornecimento, por preços acessíveis, de medicamentos àqueles que, por suas condições econômicas, não podiam adquiri-los, atuou como regulador da produção e da distribuição de medicamentos dos laboratórios farmacêuticos 5 . Em 1992, quando o CIP e a Ceme foram desativados, os preços passaram a ser apenas monitorados pelo governo, tarefa atribuída inicialmente ao Conselho Administrativo de Defesa Econômica e, posteriormente, à Secretaria de Acompanhamento Econômico do Ministério das Finanças, entre 1997-19994.

O aumento abusivo dos preços dos medicamentos e a venda de produtos farmacêuticos de qualidade duvidosa levaram, em
1999, a instauração da Comissão Parlamentar de Inquérito (CPI) dos medicamentos. Ainda nesse mesmo ano, foi criada a Agência Nacional de Vigilância Sanitária (Anvisa), com a missão institucional de proteger a saúde da população brasileira por meio do controle sanitário exercido sobre os produtos e sobre a comercialização de medicamentos ${ }^{6}$. No período subsequente, como desdobramento da CPI, ficou definida a necessidade de reduzir a escalada de preços de medicamentos e realinhá-los a patamares da década anterior. Devido a isto, houve a desoneração da tributação dos medicamentos, por meio da Lei $n^{\circ} 10.147$, de 21 de dezembro de 2000, pelo Programa de Integração Social/Contribuição para Financiamento da Seguridade (PIS/Cofins), e a desindexação dos preços de medicamentos de índices de inflação ${ }^{7,8}$.

Ainda em 2000, a Medida Provisória (MP) $\mathrm{n}^{\circ} 2.063$, de 18 de dezembro, definiu as normas de regulação para o setor de medicamentos no Brasil, instituindo a Fórmula Paramétrica de Reajuste de Preços de Medicamentos e criando a Câmara de Medicamentos. Esta MP foi convertida na Lei $\mathrm{n}^{\circ} 10.213$, de 27 de março de 2001, e, posteriormente, revogada pela Lei $\mathrm{n}^{\circ} 10.742$, de 6 de outubro de 2003, que levou a criação da Câmara de Regulação do Mercado de Medicamentos (CMED) em $2003^{6}$.

Por meio da Lei $n^{\circ} 10.742 / 2003$, estabeleceram-se, no Art. 4, as regras para o ajuste e a determinação dos preços dos medicamentos, que deveria ser baseado em um modelo de teto de preços calculado com base em um índice (Índice Nacional de Preços ao Consumidor Amplo - IPCA), em um fator de produtividade (expresso em percentual, permitindo repassar aos consumidores projeções de ganhos de produtividade das empresas) e em um fator de ajuste de preços relativos intrassetor (calculado com base no poder de mercado, determinado pelo poder de monopólio/oligopólio, assimetria de informação e barreiras à entrada) e entre setores (calculada com base na variação dos custos dos insumos, desde que tais custos não sejam recuperados pelo cômputo do índice) $)^{9}$.

A fórmula utilizada para cálculo do reajuste passou a ser:

$$
V P P=I P C A-X+Y+Z
$$

Onde VPP representa a variação percentual do preço do medicamento; IPCA representa a taxa de inflação medida pela variação percentual do IPCA; $X$ representa o fator de produtividade; $Y$ representa o fator de ajuste de preços relativos entre setores; e $\mathrm{Z}$ representa o fator de ajuste de preços relativos intrassetor ${ }^{10}$.

Por meio da Resolução n 2, de 5 de março de 200411, a CMED passou a ser responsável por controlar os preços de entrada dos medicamentos, conforme regras específicas para cada tipo: (i) produtos novos (objeto de patente e com ganho para o tratamento) - preço-fábrica (PF) não pode ser superior ao menor PF praticado nos países relacionados (Austrália, Canadá, Espanha, Estados Unidos, França, Grécia, Itália, Nova Zelândia, Portugal e o PF praticado no país de origem do produto), agregando-se os impostos incidentes; (ii) produtos novos não enquadrados na 
definição anterior - PF tem como base o custo de tratamento com os medicamentos utilizados para a mesma indicação terapêutica; (iii) nova apresentação de medicamento já comercializado pela empresa - PF não pode ser superior à média aritmética dos preços das apresentações do medicamento; (iv) não comercializado pela empresa ou já comercializado em nova forma farmacêutica - PF não pode ultrapassar o preço médio das apresentações dos medicamentos disponíveis no mercado ponderado pelo faturamento de cada apresentação; (v) nova forma farmacêutica no país ou nova associação de princípios ativos já existentes no país - PF, no caso de novas associações, não pode ser superior à soma dos preços das monodrogas, ou no caso de novas formas farmacêuticas, ao custo de tratamento com os medicamentos existentes no mercado brasileiro para a mesma indicação terapêutica; (vi) genéricos - PF não pode ser superior a $65 \%$ do preço do medicamento de referência.

Em 2012, o relatório do Acórdão $n^{\circ} 3.016$ do Tribunal de Contas da União recomendou ao Ministério da Saúde rever o modelo regulatório previsto na Lei $\mathrm{n}^{\circ} 10.742 / 2003$, de forma a desvincular os reajustes da inflação. Após ser constatado que $86 \%$ dos medicamentos de uma amostra de fármacos com maior faturamento apresentavam preço acima da média internacional, sendo 46\% com maior preço no Brasil, recomendou também a revisão periódica dos preços a partir de critérios como comparação internacional, variação cambial e custos dos diferentes tratamentos. O Acórdão deu margem a uma consulta pública, que culminou na mudança de parâmetros para cálculo do Fator $Z^{8}$. Destaca-se, porém, que a regulação define somente reajustes positivos, não havendo possibilidade de redução de preços ${ }^{7,12}$.

Este modelo regulatório, a parte suas modificações acima comentadas, já tem 16 anos. Segundo Dias et al. ${ }^{8}$, a longevidade do modelo de reajuste de preços, sem realinhamento periódico dos tetos aos preços de mercado, tem gerado preços máximos descolados da realidade, que aumentam a assimetria de informação e podem respaldar futuros aumentos abusivos. 0 modelo regulatório em vigor permanece sem qualquer realinhamento, com consequentes distorções acumuladas entre Preço Máximo ao Consumidor (PMC) e preços praticados. Além disto, não há um monitoramento efetivo dos preços dos medicamentos nos pontos de venda pela CMED ${ }^{12}$.

Desse modo, dado que a regulação no Brasil não tem levado a resultados satisfatórios ${ }^{8,12}$ e ao enorme período sem modificações expressivas, buscou-se realizar um levantamento da literatura internacional acerca de modelos regulatórios aplicados aos preços de medicamentos em outros países para buscar aprendizados para o Brasil. Sendo assim, o objetivo deste artigo foi discutir, com base em outras experiências de regulação de preços de medicamentos em países selecionados, a regulação de preços de medicamentos no Brasil, de modo a acumular evidências da necessidade de melhorias na regulação em vigor.

\section{MÉTODO}

Para a revisão de literatura foi realizada uma busca eletrônica nas bases de dados Google Scholar e Science Direct, as quais foram escolhidas por serem bases mais amplas e por possuírem artigos de diversas áreas e países. Na busca foram utilizadas as palavras-chave: "medicamentos genéricos", "generic drug" e "international price comparisons". Essa pesquisa resultou na seleção de 92 textos, dos quais foram excluídos aqueles que não mencionavam "regulação de preços" e que não eram artigos publicados em periódicos, restando 34 artigos. Após a leitura do resumo desses 34 artigos, foram selecionados 12 que apresentavam modelos regulatórios de preços de medicamentos em diversos países. Após a leitura detalhada dos 12 artigos, foram utilizados apenas os seguintes: Brekke et al. ${ }^{13}$, Dylst e Simoens ${ }^{14}$, Simoens ${ }^{15}$, Vogler ${ }^{16}$ e Wouters e Kanavos ${ }^{17}$. Foi realizada uma nova busca no Science Direct, utilizando-se a palavra-chave "precio de medicamentos", que resultou em um total de 51 artigos. Após uma breve leitura do título e do resumo, foram selecionados quatro artigos que descreviam a forma de atuação da regulação de preços de medicamentos em algum PED, destes apenas foi utilizado o artigo de Vacca et al. ${ }^{18}$. Por meio da leitura destes artigos, foi realizada a seleção de artigos referenciados, os quais foram inseridos na base. Além dessa busca sistemática, foram acrescentados artigos conhecidos previamente. Ao final, a base possuía 17 artigos.

Essa revisão de literatura serviu para observar como ocorre a regulação de preços dos medicamentos em distintos países, comparando estas regulações com a brasileira e levando a evidência de sugestões de como aperfeiçoar a regulação brasileira atual para se alcançar resultados mais desejáveis. A sistematização da literatura foi feita por grupo de países, a saber, países europeus e PED.

\section{RESULTADOS}

Esta seção está dividida em três partes: a primeira trata da regulação de preços de medicamentos nos países europeus, apresentando os tipos de regulação nestes países; a segunda, das vantagens e desvantagens dessas regulações nos países europeus; e a terceira, sobre a regulação de preços de medicamentos em PED.

Tipos de regulação de preços de medicamentos nos países europeus

$\mathrm{Na}$ Europa, os sistemas de precificação de medicamentos tendem a adotar: a) um sistema de preços regulados, com preços sendo estabelecidos por uma base regulatória; b) uma abordagem de livre mercado, em que os fabricantes são (relativamente) livres para fixar os preços; ou c) uma combinação destas abordagens ${ }^{15}$.

Dentre os países europeus, apenas Malta, Dinamarca e Alemanha não possuíam controle estatal de preços de medicamentos no setor privado, sendo conhecidos como países de "preços livres". Na Bélgica, República Tcheca, Chipre, Grécia, Letônia e Luxemburgo, todos os medicamentos eram preços-controlados. Na Bulgária, Holanda, Portugal e Romênia, apenas os preços dos genéricos de prescrição eram controlados ${ }^{19}$. No Quadro 1 , é possível observar as três principais formas de regulação implementadas em países europeus, uma breve descrição de sua metodologia e os países que as aplicam.

Quanto ao modelo de vinculação de preços dos genéricos, na Áustria, o primeiro genérico era considerado economicamente eficiente se o seu preço fosse pelo menos $48 \%$ abaixo do de 
Quadro 1. Tipos de regulações implementadas em países europeus.

\begin{tabular}{|c|c|c|}
\hline Regulação & Metodologia & Países \\
\hline $\begin{array}{l}\text { Vinculação de preços } \\
\text { dos genéricos }\end{array}$ & $\begin{array}{l}\text { Preços dos medicamentos genéricos são determinados em uma } \\
\text { porcentagem abaixo do preço do medicamento de referência. }\end{array}$ & $\begin{array}{c}\text { República Tcheca, Grécia, Irlanda, Itália e Luxemburgo (até } \\
20 \% \text { abaixo); Bélgica, Chipre (medicamentos produzidos } \\
\text { localmente); Hungria, Polônia e Portugal (de } 20-50 \% \text { abaixo); } \\
\text { França (pelo menos } 50 \% \text { abaixo) }{ }^{19} \text {. }\end{array}$ \\
\hline PRE & $\begin{array}{l}\text { Prática de usar o preço de um medicamento em um ou vários } \\
\text { países para obter um preço de referência com o objetivo de } \\
\text { definir ou negociar o preço em um determinado país. }\end{array}$ & $\begin{array}{l}\text { Segundo Vogler }{ }^{16}, 25 \text { países europeus utilizavam o PRE para } \\
\text { determinar os preços dos medicamentos e apenas Dinamarca, } \\
\text { Suécia e Reino Unido não aplicavam o PRE. }\end{array}$ \\
\hline PRR & $\begin{array}{l}\text { Implica agrupar produtos idênticos ou similares nos chamados } \\
\text { grupos de referência, determinando um valor máximo de } \\
\text { reembolso a ser coberto por terceiros. O paciente paga } \\
\text { apenas a diferença entre o PRR e o preço na farmácia. }\end{array}$ & $\begin{array}{l}\text { Bélgica, Bulgária, Dinamarca, Eslovênia, Espanha, Estônia, } \\
\text { França, Finlândia, Grécia, Itália, Lituânia, Noruega, Portugal } \\
\text { (ATC 5); Alemanha, Croácia, Eslováquia, Holanda, Hungria, } \\
\text { Letônia, Polônia, República Tcheca, Romênia (clusters) }{ }^{16} \text {. }\end{array}$ \\
\hline
\end{tabular}

Fonte: Elaborado pelos autores, 2020.

PRE: Preço de referência externa; PRR: Preço de referência para reembolso.

referência, e a eficiência econômica era assumida se o segundo, e cada seguidor subsequente, oferecesse uma diferença de preço suficientemente grande em relação ao genérico incluído anteriormente. Além disso, o preço do medicamento de referência deveria ser reduzido em pelo menos $30 \%$ dentro de três meses após a inclusão do primeiro genérico ${ }^{19}$.

Para o preço de referência externa (PRE), pode-se adotar diferentes métodos para escolhê-lo ou calculá-lo levando em consideração: (i) a cesta dos países de referência; (ii) a data do preço (atual ou no lançamento); e, (iii) o cálculo do preço de referência (menor preço, média simples ou ponderada). 0 valor resultante pode ser ajustado por um parâmetro específico para levar em conta a menor capacidade econômica do país em relação aos países de referência. Além disso, os países europeus tendiam a selecionar como países de referência aqueles que compartilhavam semelhanças econômicas, proximidade geográfica ou disponibilidade de informações sobre preços. Na Estônia, por exemplo, o PRE é usado para medicamentos de referência reembolsados e genéricos, toma como referência todos os estados-membros da União Europeia, mas examina explicitamente os preços da Letônia, Lituânia e Hungria. A Letônia e a Lituânia foram escolhidas por serem os países mais próximos, com situação econômica, estrutura populacional e status epidemiológico semelhantes. A Hungria foi escolhida por possuir um procedimento de preços semelhante'1.

As políticas voltadas para o controle de preços de venda ao consumidor podem ainda estar sujeitas a controle das margens de comercialização, a definição de critérios de fixação dos preços iniciais de venda e regras para reajustes futuros de preços. Em Portugal, o sistema nacional de saúde negociava o preço com o laboratório e estabelecia o preço de venda ao consumidor, controlando as margens de comercialização. Além disso, os preços eram revistos anualmente de acordo com a variação da inflação, podendo haver anos em que a revisão não era autorizada ${ }^{20}$.

Vantagens e desvantagens dos diferentes tipos de regulação de preços de medicamentos nos países europeus

Segundo Simoens ${ }^{15}$, os PF dos genéricos variavam substancialmente tanto entre países quanto dentro de um mesmo país, o que sugeria que os preços não apenas refletiam os custos de produção subjacentes, mas que também eram influenciados pelo ambiente regulatório em torno do registro, precificação, reembolso e distribuição. Wouters e Kanavos ${ }^{17}$ observaram que os PF e de varejo de uma amostra de genéricos variaram muito entre sete países europeus. Dinamarca e Suécia tinham os preços mais baixos entre os sete países, enquanto França e Itália tinham os mais altos na maioria dos índices ponderados. Os autores verificaram que: (i) a variação de preços diferia entre os grupos terapêuticos e devido a diferenças na regulação das margens de atacadistas e varejistas; e (ii) os pacientes tendiam a consumir mais dos medicamentos que eram mais baratos em seus países.

Foi observado ainda que países que não exigiam explicitamente que os genéricos fossem precificados a uma determinada porcentagem mais baixa relatavam diferenças consideráveis de preço em relação aos de referência (por exemplo: Holanda e Eslováquia), e atribuíam isto à concorrência. Além disso, a penetração dos genéricos era mais bem-sucedida em países com livre precificação do que com regulação. Isto ocorria porque, em países com livre mercado, os fabricantes dos medicamentos de referência podiam cobrar preços mais elevados, antes e depois da expiração da patente, atraindo a entrada de genéricos. Os genéricos, por sua vez, eram capazes de aumentar seu market-share oferecendo reduções de preço. A principal conclusão foi que, se por um lado, a diferença de preço entre genéricos e de referência tendia a ser maior em países de preços livres devido à concorrência, por outro, a regulação tendia a reduzir o preço do medicamento de referência sobre seu ciclo de vida, o que desencorajava a entrada de genéricos ${ }^{15,16}$.

Além disso, Dylst e Simoens ${ }^{14}$ observaram que os níveis mais altos de preços dos genéricos estavam no Reino Unido, França, Holanda e Alemanha, e isto ocorria porque a concorrência entre os fabricantes de genéricos assumia a forma de descontos para a cadeia de distribuição. Segundo os autores, este tipo de concorrência não é transparente para os atores do mercado e não é justa, pois atacadistas e varejistas são recompensados por sua capacidade de negociar descontos em preços artificiais, tendendo a superestimar o preço dos genéricos. Por causa disso, a França passou a regular o tamanho desses descontos. Por outro lado, os autores observaram que a concorrência de preços de genéricos é transparente para todos os atores do mercado, garantindo que os preços pagos reflitam o valor real do produto e sendo capazes de reduzir os preços de medicamentos de referência. 
Quanto aos problemas referentes à utilização do PRE, notou-se que, na Alemanha, algumas empresas haviam decidido manter altos os preços de alguns medicamentos, apesar dos preços de referência interna (PRI) serem mais baixos, o que levava a perda subsequente de participação no mercado. Isto ocorreu porque as empresas sabiam que os preços neste país mais tarde se tornariam referências para outros países. Desse modo, ao manter os preços altos na Alemanha, as empresas eram capazes de obter preços mais altos em outros países. Portanto, uma consequência do PRE é pressionar os países selecionados como referência a manter preços altos ${ }^{1}$.

Quanto à utilização do preço de referência para reembolso (PRR), Brekke et al. ${ }^{13}$ observaram que, na Noruega, este mecanismo era capaz de reduzir significativamente os preços de medicamentos de marca e de genéricos no grupo de referência, dado que este mecanismo visa estimular a concorrência e assim torna a demanda por medicamentos mais elástica. Enquanto isso, com o price-cap (PC), que era obrigatório apenas para os medicamentos de marca, foi observada uma grande redução de preço nos genéricos, enquanto os de marca obtinham apenas reduções abaixo do teto. Com isto, Brekke et al. ${ }^{13}$ sugeriram que o PRR era mais eficaz do que o PC na redução dos preços.

A regulação de preços nos países em desenvolvimento: América Latina, África e Ásia

Nesta seção são discutidos modelos regulatórios de preços de medicamentos em PED. Nesses países, os gastos com medicamentos representam $25-66 \%$ do total dos gastos públicos e privados em saúde e, portanto, representam a maior despesa familiar após alimentação ${ }^{21}$. A maior parte da população desses países não é portadora de planos de saúde e depende do sistema público para o acesso a medicamentos. 0 mecanismo de reembolso fortemente utilizado nos sistemas europeus, quando o setor público arca com a despesa ou parte dela (copagamento), é tanto um regulador eficiente de preços quanto um estimulador do aumento da participação dos genéricos no mercado. A ausência desses mecanismos nos PED, ou em parte deles, mostra a importância da regulação de preços dos medicamentos.

Todavia, como destacaram Kaplan et al. ${ }^{19}$ e Ali e Yahia ${ }^{22}$, estudos publicados sobre a forma como os governos dos PED regulam os preços dos medicamentos são relativamente escassos. No Quadro 2 são apresentados alguns modelos de regulação que vigoram em PED.

Como consta no Quadro 2, na Colômbia, são estabelecidos três regimes: (a) Liberdade Supervisionada, que aceita o preço estabelecido pelo fabricante com o compromisso de relatar variações e a determinação dos preços à Comisión Nacional de Precios de Medicamentos (entidade que determina o regime no qual um medicamento entra); (b) Regime de Liberdade Regulada (RLR), no qual ingressam os medicamentos que servem para proteger a saúde pública, com alta concentração de mercado ou sem substitutos ao entrar no mercado. Calcula-se um PRE (média dos três preços mais baixos dos mesmos medicamentos produzidos pela mesma empresa matriz nos países de referência e no mesmo nível da cadeia de distribuição), estabelecido como preço máximo. Em 2010, os países tomados como referência eram: Argentina, Brasil, Chile, Colômbia, Equador,

Quadro 2. Modelos de regulação de preços de medicamentos em países em desenvolvimento (PED).

\begin{tabular}{|c|c|}
\hline País & Modelo de regulação \\
\hline Colômbia & $\begin{array}{l}\text { Desde 2006, são estabelecidos três regimes: (a) Regime de Liberdade Supervisionada; (b) RLR; (c) Regime de Controle Direto. Além do } \\
\text { PRE, também se utiliza uma metodologia de análise de minimização de custos, selecionando medicamentos comparáveis e avaliando } \\
\text { os custos do tratamento }{ }^{18} \text {. }\end{array}$ \\
\hline México & $\begin{array}{l}\text { Desde 2004, a regulação de preço máximo: (a) se aplica apenas a medicamentos protegidos por patente vendidos no setor privado; } \\
\text { (b) tem participação voluntária dos fabricantes; (c) usa o PRE para estabelecer o limite para o PMVP; (d) para novos produtos } \\
\text { sem comparadores, permite que o fabricante defina o preço, sujeito a reavaliação após três meses; e (e) isenta da regulação de } \\
\text { medicamentos genéricos e de referência cujas patentes expiraram }{ }^{23} \text {. }\end{array}$ \\
\hline África do Sul & $\begin{array}{l}\text { Em 1996, desenvolveu uma Política Nacional de Medicamentos, a qual levou posteriormente a medidas para o controle de preços de } \\
\text { fabricantes, entre elas o chamado "preço único de saída", assim como uma taxa única fixa de distribuição ou dispensação. O uso de } \\
\text { licitações é limitado ao setor público }\end{array}$ \\
\hline Sudão & $\begin{array}{l}\text { Em 2009, a lei que regula os preços dos medicamentos passou a ser denominada como "Lei de Medicamentos e Venenos". Antes da } \\
\text { comercialização, um medicamento deve ser registrado no NMPB, o qual aprova um preço C\&F. Com base no C\&F total, o NMPB fixa } \\
\text { as porcentagens máximas de mark-up (margem para cobrir os custos fixos e o lucro) para todos os medicamentos em duas etapas de } \\
\text { distribuição: atacadista, } 15 \% \text { dos custos totais, e varejista, } 20 \% \text { do preço do atacadista }{ }^{22} \text {. }\end{array}$ \\
\hline China & $\begin{array}{l}\text { Segundo Tang et al. apud Kaplan et al. }{ }^{19} \text {, em } 2006 \text {, o mecanismo para definir o preço máximo de varejo baseava-se em: i) custo de } \\
\text { produção; ii) spread de preço de atacadista estabelecido pelo governo; e iii) preços de produtos comparáveis no mercado. Porém, os } \\
\text { preços são estabelecidos no nível desejado pelos fabricantes. }\end{array}$ \\
\hline Filipinas & $\begin{array}{l}\text { Em 2008, foi assinada a política de controle de preços de medicamentos, com a definição de um preço máximo de varejo para uma } \\
\text { lista de medicamentos que se enquadram na Universally Accessible Cheaper and Quality Medicine Act of 2008. Medicamentos de } \\
\text { marca sob patente eram o principal alvo das leis de controle de preços }{ }^{19} \text {. }\end{array}$ \\
\hline Índia & $\begin{array}{l}\text { Em 2012, a Índia aprovou uma nova política de preços projetada para aumentar o número de medicamentos essenciais com controle } \\
\text { de preços. A legislação é projetada para reduzir os preços de medicamentos de marca. Sob a nova política, um sistema PRI, o } \\
\text { preço-limite de um medicamento em particular é calculado pela média dos preços de todas as marcas com mais de } 1 \% \text { de participação } \\
\text { de mercado }{ }^{19} \text {. Ademais, os preços dos medicamentos que não estão com controle de preços também são regulados até certo ponto, em } \\
\text { que o governo garante que os preços não aumentem em mais de } 10 \% \text { em um ano }{ }^{25} \text {. }\end{array}$ \\
\hline Tailândia & $\begin{array}{l}\text { Emprega algumas políticas para controlar indiretamente os preços e despesas de medicamentos no setor público, como: a } \\
\text { implementação da Lista Nacional de Medicamentos, os Esquemas Nacionais de Seguro de Saúde e a utilização do Grupo Relacionado a } \\
\text { Medicamentos para reembolsar as despesas de internação de funcionários do governo }{ }^{26} \text {. }\end{array}$ \\
\hline
\end{tabular}

Fonte: Elaborado pelos autores, 2020.

PRE: Preço de referência externa; RLR: Regime de Liberdade Regulada; C\&F: custo e frete; PMVP: Preço máximo de venda ao público; NMPB: National Medicines and Poisons Board; PRI: Preços de referência interna. 
México, Panamá, Peru e Uruguai; (c) Caso um medicamento na RLR exceda o preço limite, ele passa para o Controle Direto, no qual se define diretamente um limite para o preço máximo de venda ao público (PMVP) com base no PRE ${ }^{18}$.

No México, a regulação de preço máximo é administrada pelo Ministério da Economia, com as características apresentadas no Quadro 2. Os genéricos são isentos dessa regulação, pois argumenta-se que a concorrência elimina a lógica da regulação $0^{23}$. Porém, embora a oferta de genéricos no país tenha aumentado significativamente nos anos 2000, a sua participação permaneceu baixa em comparação com outros países, em parte devido aos preços altos $^{27}$. Além disso, são definidos três preços: (i) o PRE, calculado como a média ponderada dos PF do trimestre anterior nos seis países em que o produto possui a maior penetração de vendas. 0 fabricante deve submeter ao Ministério da Economia a cada ano o PRE, que está sujeito a verificação anual por um auditor externo; (ii) o preço de referência para venda ao público (PRVP), decorrente da multiplicação do PRE por 1,72, e convertido em pesos usando a taxa de câmbio média calculada pelo Banco Central do México correspondente ao período em que o PRE foi calculado; (iii) o PMVP, preço permitido para um medicamento sob patente definido pelo fabricante e impresso na etiqueta do produto. Se o PMVP ou os aumentos propostos resultarem em um PMVP maior que o PRVP, o primeiro deverá se ajustar para baixo em relação ao PRVP. A Procuraduría Federal del Consumidor é a responsável por garantir o cumprimento dos preços máximos estabelecidos e monitorar a adesão das farmácias à lei² ${ }^{23}$.

Na África do Sul, como mencionado no Quadro 2, a partir da Política Nacional de Medicamentos, foi sinalizada uma série multifacetada de intervenções para reduzir os preços dos medicamentos e melhorar as práticas de prescrição e distribuição. 0 preço único de saída é o único preço pelo qual os fabricantes podem vender o medicamento a qualquer entidade que não seja o Estado, e uma única taxa fixa de distribuição ou dispensação destinava-se a controlar os custos na cadeia de distribuição ${ }^{24}$.

No Sudão, além das informações presentes no Quadro 2, o certificado do medicamento era válido por cinco anos, sendo permitidas alterações nos preços em resposta a mudanças nas circunstâncias econômicas, como flutuações na taxa de câmbio e ajustes na inflação. 0 governo tributava $1,5 \%$ dos preços de compra no caso dos varejistas e cobrava um imposto de mark-up de $15,0 \%$ a ser pago pelos importadores. Os importadores eram obrigados a estampar o preço nas embalagens. No setor público, as compras eram realizadas pela Central Medical Supplies Public Corporation (CMSPC), sendo o preço custo e frete (C\&F) determinado pelo Comitê de Licitação. Os produtos da CMSPC eram vendidos para instituições de saúde públicas e privadas com um mark-up de 20,0\% e 12,0\% para os Revolving Medicine Funds nos níveis estaduais. Cada nível adicionava seu mark-up antes que os medicamentos fossem vendidos aos consumidores ${ }^{22}$.

Segundo Tang et al. apud Kaplan et al. ${ }^{19}$, em 2006, na China, os hospitais tinham o monopólio da compra de medicamentos e suas finanças dependiam fortemente da venda de medicamentos. Para aliviar o ônus das despesas médicas e garantir a implementação do plano de seguro médico, eram regulados os preços de varejo dos medicamentos qualificados para o programa e incluídos no National Basic Medical Insurance Scheme Drug Catalogue.

Em 2012, a Índia aprovou, como mencionado no Quadro 2, a Política Nacional de Precificação de Produtos Farmacêuticos. Dos novos medicamentos incluídos nessa política, 348 são definidos como essenciais. Com a prerrogativa de incentivar o investimento, esta política estabelece que medicamentos patenteados sob o Indian Patents Act de 1970, e que são resultado de produtos ou processos endógenos, ficam isentos de controle de preços por um período de cinco anos, assim como uma formulação que envolve um novo sistema de entrega desenvolvido por meio de P\&D endógena ${ }^{19,28}$.

Na Tailândia, em 2006, cerca de 60\% dos medicamentos no país eram importados. Ademais, a aquisição dos hospitais públicos ocorria por meio de mecanismos de compra em grupo, e os preços de varejo estabelecidos não eram controlados pelo governo, mas as empresas notificavam as autoridades os aumentos de preços. Os mark-ups nos genéricos eram consideravelmente mais altos do que nos medicamentos de marca, no entanto, os preços dos medicamentos de marca eram mais de quatro vezes superiores aos dos genéricos ${ }^{26}$.

\section{DISCUSSÃO}

A análise da regulação de preços de medicamentos no Brasil, em perspectiva com a literatura internacional, fornece alguns exemplos e pontos para reflexão que podem gerar melhorias na regulação em vigor. Por exemplo, enquanto no Brasil não há distinção na regulação de preços para produtos inovadores desenvolvidos internamente, a Índia, como mostrado acima, deixa isentos de controle de preços por um período de cinco anos os produtos ou processos desenvolvidos endogenamente e o mesmo ocorre para formulações com um novo sistema de entrega desenvolvido por meio de P\&D endógena ${ }^{19,28}$. Isso mostra que a regulação atual de preços de medicamentos no Brasil não gera incentivos para que se realizem esforços inovativos no país. Assim, o exemplo da Índia mostra que a regulação de preço brasileira perde a oportunidade de estimular a entrada de medicamentos inovadores, principalmente aqueles que são introduzidos pelas empresas brasileiras com inovações incrementais.

Outro exemplo internacional que traz reflexões sobre a regulação brasileira diz respeito à regulação de preços dos medicamentos genéricos. Na Áustria, para cada seguidor de genérico subsequente, deveria haver uma diferença de preço suficientemente grande em relação ao genérico incluído anteriormente e, além disso, o preço do medicamento de referência também deveria ser reduzido ${ }^{19}$. Desta forma, a regulação em vigor no Brasil poderia alcançar resultados mais desejáveis, em relação ao preço dos genéricos, se o diferencial de preço de entrada destes medicamentos, em relação ao medicamento de referência, fosse maior que $35 \%$ e se fosse incentivada a redução do preço dos genéricos subsequentes pela regulação.

Os dois parágrafos anteriores mostram que a regulação brasileira não está alinhada com as políticas públicas de genéricos e de 
incentivo à inovação, como encontrado em alguns países. Logo, a regulação de preços não está atingindo os objetivos listados por Espin et al. ${ }^{1}$, que indicam que um sistema ótimo de regulação de preços deve: (i) estar alinhado com os objetivos de política previamente acordados; (ii) garantir acessibilidade, sustentabilidade financeira e qualidade do produto; (iii) ser direcionado para atingir preços mais baixos do que aqueles que de outra forma prevaleceriam; (iv) ser capaz de melhorar a inovação, a disponibilidade e a produção doméstica; e (v) ser fácil, objetivo, transparente, previsível e não muito caro para administrar.

A regulação brasileira do preço dos medicamentos parece ter sido inspirada naquelas que já vigoravam nos países europeus quando foi criada a CMED. Porém, algumas recomendações têm sido propostas para que, em conjunto com a regulação de preços, ou por meio da sua modificação, países europeus com baixa participação de genéricos possam ampliar o seu uso e garantir uma melhor eficiência em seus mercados. Algumas recomendações são válidas também para o caso brasileiro, como as listadas no estudo da Medicines for Europe ${ }^{30}$, resumidas no Quadro 3.

Foi observada uma grande preocupação no estudo da Medicines for Europe $e^{30}$ para que a redução de preços dos genéricos não leve ao desabastecimento de medicamentos, devendo haver equilíbrio entre disponibilidade e preço. Este não parece ser o caso do Brasil, sobretudo observado o grande número de fornecedores atuando no mercado varejista ${ }^{29}$. Além disso, tanto a vinculação do preço dos genéricos aos medicamentos de referência como a própria margem administrada no Brasil foram recomendadas a outros países. Para uma parte dos países europeus foi recomendado reduzir a margem.

No México, por exemplo, acreditava-se que os preços dos genéricos poderiam ser definidos pela concorrência, sem necessidade de regulação ${ }^{23}$. Entretanto, a consequência disto foi um baixo mercado de genéricos no país devido aos altos preços ${ }^{27}$, situação distinta dos países europeus, talvez devido às diferenças dos mercados e formas de regulação. Também foram observadas críticas à aplicação do reajuste anual do preço para os genéricos, em que se assume que o preço dos genéricos já está vinculado ao preço do medicamento de referência. Deste modo, desde que exista um método de reajuste anual de preços para o medicamento de referência, qualquer alteração no preço deste já afetará o preço do respectivo genérico ${ }^{30}$.

Brekke et al. ${ }^{13}$ mostraram que, na Noruega, quando vigorava o PC (compulsório apenas para o medicamento de referência), o preço do medicamento de referência tendia a flutuar próximo ao teto, enquanto o do genérico se reduzia bastante. O PC é utilizado no
Brasil para o reajuste de preços de medicamentos genéricos e de referência. Entretanto, os medicamentos de referência têm mantido seus preços mais próximos ao teto do que os genéricos, que tendem a descolar o seu preço praticado do PMC ${ }^{29}$. Desta maneira, a revisão de preços para os genéricos por PC no Brasil, pode estar levando à não efetividade da regulação atual.

Foram observadas outras críticas ao modelo de reajuste anual de preços no Brasil, principalmente no tocante à determinação dos fatores e à falta de clareza na forma como são calculados. Como mostraram Dias et al. $^{8}$, na determinação do Fator X, quanto menor a produtividade estimada, maior o aumento permitido. Isto pode ser um problema, pois, de certa forma, a regulação não está incentivando as empresas a ampliarem a sua produtividade, visando obter reajustes maiores. Na determinação do Fator $Y$, os valores negativos são acumulados e descontados em momentos futuros de aumento dos custos de produção. Para os genéricos, os custos de produção tendem a diminuir com o tempo, o que pode estar contribuindo para a determinação de PMC mais elevados. Podem ainda existir outros fatores contribuindo para a queda de custos, que estão sendo acumulados e não descontados, levando a, mais uma vez, o descolamento do PMC dos preços praticados no mercado.

Além disso, como já mencionado, não há nenhum monitoramento dos preços nos pontos de venda pela CMED ${ }^{12}$ para checar esses descolamentos, cabendo apenas ao órgão de proteção e defesa do consumidor fiscalizar as relações de consumo ${ }^{31}$. Todavia, o processo de fiscalização tende a ocorrer apenas quando há reclamação por parte dos consumidores ${ }^{31}$.

A principal crítica, no caso do Brasil, à utilização do PRE é quanto à seleção dos países utilizados como referência. Todos possuem um nível de renda mais elevado, e não são consideradas nem a proximidade geográfica nem as semelhanças econômicas, sanitárias e de desembolso, não refletindo a dinâmica do mercado nacional. As discussões sobre este ponto deixam bem evidente a necessidade de aceitar as particularidades de cada país na determinação dos preços dos medicamentos. A Colômbia, por exemplo, em 2010, já utilizava como referência países com maior proximidade geográfica e semelhanças econômicas ${ }^{18}$, devendo este ponto ser revisado na regulação em vigor no Brasil. Além disso, em 2013, a Colômbia realizou um projeto técnico para propor mudanças na regulação em vigor ${ }^{32}$, mostrando a importância de que sejam feitos estudos destinados a verificar a efetividade do modelo regulatório e que sejam modificados fatores que impeçam essa maior efetividade.

Quadro 3. Recomendações para ampliar o mercado de genéricos na Europa.

\begin{tabular}{|c|c|c|}
\hline País & Recomendações de política & \\
\hline Bulgária & $\begin{array}{l}\text { Evitar, ou pelo menos otimizar, a vinculação de preço dos genéricos (a relação de preço com o } \\
\text { medicamento de referência é de } 30 \% \text {, sugerindo-se que esta porcentagem seja reduzida). }\end{array}$ & $\begin{array}{l}\text { Evitar, ou otimizar, a utilização do } \\
\text { PRE para os genéricos. }\end{array}$ \\
\hline França & $\begin{array}{c}\text { Evitar reduções de preços para os genéricos (que recebe } 60 \% \text { do preço do medicamento de } \\
\text { referência antes da expiração da patente). }\end{array}$ & $\begin{array}{l}\text { Evitar, ou otimizar, a utilização do } \\
\text { PRE para os genéricos. }\end{array}$ \\
\hline Portugal & Limitar a redução do preço dos novos genéricos a $65 \%$ do preço do medicamento de referência. & $\begin{array}{l}\text { Abolir a revisão anual de preços } \\
\text { de genéricos. }\end{array}$ \\
\hline
\end{tabular}

Fonte: Elaborado pelos autores segundo Medicines for Europe ${ }^{30}, 2020$.

PRE: Preço de referência externa. 
Por fim, há críticas ao modelo de concorrência por descontos na cadeia de distribuição, mostrando-se que estes levam a preços mais altos do que aqueles que vigorariam na concorrência por preço ${ }^{14}$. No Brasil, este é o tipo de concorrência que tem se observado para os genéricos. Porém, tendo em vista as críticas sobre a falta de clareza dos preços reais quando vigora este tipo de concorrência, deveria se observar de que modo isto pode estar atrapalhando o crescimento da participação dos genéricos no mercado nacional e, até mesmo, levando à prática de preços mais elevados. Deveria haver maior controle da agência reguladora no que diz respeito a este ponto e, talvez, ser estabelecida algum tipo de regulação a estes descontos na cadeia de distribuição.

\section{CONCLUSÕES}

O modelo regulatório de preços de medicamentos no Brasil está em vigor há 16 anos sem quaisquer alterações significativas.
Com isso, tem-se observado a determinação de preços máximos totalmente descolados dos preços praticados no mercado ${ }^{8,12,29} \mathrm{e}$ nenhum monitoramento dos preços nos pontos de venda pela CMED ${ }^{12}$, produzindo resultados insatisfatórios.

A revisão da literatura internacional serviu para observar como ocorre a regulação de preços de medicamentos em distintos países, comparando estas regulações com a brasileira e levando à evidência de sugestões de como poderia se aperfeiçoar a regulação atual para alcançar resultados mais desejáveis.

Assim, destaca-se a necessidade de análises mais profundas das características dos mercados estudados para identificação das possibilidades de aplicação de tais medidas no mercado brasileiro. Este artigo abre a discussão sobre a necessidade de debate, reflexões e avaliações sobre a regulação de preços de medicamentos no Brasil e indica caminhos para aprofundamentos futuros sobre modelos regulatórios mais eficazes do que o atual.

\section{REFERÊNCIAS}

1. Espin J, Rovira J, Labry AO. WHO/HAl project on medicine prices and availability: review series on pharmaceutical pricing policies and interventions: working paper 1 : external reference pricing. Geneva: World Health Organization; 2011.

2. Hasenclever $\mathrm{L}$, coordenador. Diagnóstico da indústria farmacêutica brasileira. Brasília: Representação da Unesco do Brasil; 2002.

3. Sood N, Vries H, Gutierrez I, Lakdawalla DN, Goldman DP. The effect of regulation on pharmaceutical revenues: experience in nineteen countries. Health Aff. 2008;27(Supl.1):125-37. https://doi.org/10.1377/hlthaff.28.1.w125

4. Nóbrega OT, Marques AR, Araújo ACG, Karnikowski MGO, Naves JOS, Silver LD. Retail prices of essential drugs in Brazil: an international comparision. Rev Panam Salud Publica. 2007;22(2):118-23.

5. Brasil. Decreto $N^{\circ} 68.806$, de 25 de junho de 1971. Institui a Central de Medicamentos (CEME). Diário Oficial União. 25 jun 1971.

6. Kornis GEM, Braga MH, Fagundes M, Paula PAB. A regulação em saúde no Brasil: um breve exame das décadas de 1999 a 2008. Physis. 2011;21(3):1077-102. https://doi.org/10.1590/S0103-73312011000300017

7. Sarai L, Pscheidt KR. Regulação de preços de medicamentos: o estado está no caminho certo? Rev Direito Econ Socioambiental. 2018;9(2):140-72. https://doi.org/10.7213/rev.dir.econ.soc.v9i2.14723

8. Dias LLS, Santos MAB, Pinto CDBS. Regulação contemporânea de preços de medicamentos no Brasil: uma análise crítica. Saude Deb. 2019;43(121):543-58. https://doi.org/10.1590/0103-1104201912120

9. Brasil. Lei $\mathrm{N}^{\circ} 10.742$, de 6 de outubro de 2003. Define normas de regulação para o setor farmacêutico, cria a Câmara de Regulação do Mercado de Medicamentos CMED e altera a lei № 6.360, de 23 de setembro de 1976, e dá outras providências. Diário Oficial União. 7 out 2003.

10. Câmara de Regulação do Mercado de Medicamentos - CMED. Resolução № 1, de 27 de fevereiro de 2004. Estabelece os critérios de composição de fatores para o ajuste de preços de medicamentos. Diário Oficial União. 1 mar 2004.

11. Câmara de Regulação do Mercado de Medicamentos - CMED. Resolução $N^{\circ} 2$, de 5 de março de 2004. Aprova os critérios para definição de preços de produtos novos e novas apresentações de que trata o artigo 7 da lei $\mathrm{N}^{\circ} 10.742$, de 6 de outubro de 2003. Diário Oficial União. 6 maio 2004.

12. Miziara NM, Coutinho DR. Problemas na política regulatória do mercado de medicamentos. Rev Saude Publica. 2015;49:1-6. https://doi.org/10.1590/S0034-8910.2015049005779

13. Brekke KR, Grasdal AL, Holmas TH. Regulation and pricing of pharmaceuticals: reference pricing or price cap regulation? Eur Econ Review. 2009;53(2):170-85. https://doi.org/10.1016/j.euroecorev.2008.03.004

14. Dylst $P$, Simoens $S$. Generic medicine pricing policies in Europe: current status and impact. Pharmaceuticals. 2010;3(3):471-81. https://doi.org/10.3390/ph3030471

15. Simoens S. A review of generic medicine pricing in Europe. Gener Biosim Init J. 2012;1(1):8-12. https://doi.org/10.5639/gabij.2012.0101.004

16. Vogler $\mathrm{S}$. The impact of pharmaceutical pricing and reimbursement policies on generics uptake: implementation of policy options on generics in 29 european countries: an overview. Gener Biosim Init J. 2012;1(2):44-51. https://doi.org/10.5639/gabij.2012.0102.020

17. Wouters OJ, Kanavos PG. A comparison of generic drug prices in seven european countries: a methodological analysis. BMC Health Serv Res. 2017;17(1):1-7. https://doi.org/10.1186/s12913-017-2184-5 
18. Vacca C, Acosta A, Rodriguez I. Precios de referencia internacional y análisis de costo minimización para la regulación de precios de medicamentos en Colombia. Val Health. 2011;14(1):s16-9. https://doi.org/10.1016/j.jval.2011.05.034

19. Kaplan W, Wirtz V, Nguyen A, Ewen M, Vogler S, Laing R. Policy options for promoting the use of generic medicines in low- and middle-income countries. Amsterdam: Health Action International; 2016.

20. Rêgo ECL. Políticas de regulação do mercado de medicamentos: a experiência internacional. Rev BNDES. 2000;7(14):367-99.

21. Babar ZUD, Ramzan S, El-Dahiyat F, Tachmazidis I, Adebisi A, Hasan SS. The availability, pricing, and affordability of essential diabetes medicines in 17 low-, middle-, and high-income countries. Front Pharmacol. 2019;10:1-10. https://doi.org/10.3389/fphar.2019.01375

22. Ali GKM, Yahia AY. Controlling medicine prices in Sudan: the challenge of the recently established medicines regulatory authority. East Mediterr Health J. 2012;18(8):811-20. https://doi.org/10.26719/2012.18.8.811

23. Moïse $P$, Docteur E. Pharmaceutical pricing and reimbursement policies in Mexico. Paris: Organization for Economic Co-operation and Development; 2007.

24. Gray AL. Medicine pricing interventions: the South African experience. Southern Med Review. 2009;2(2):15-9.

25. Kohli S. National pharmaceutical policy 2012. SpicylP. 23 dez 2012[acesso 11 out 2019]. Disponível em: https://spicyip. com/2012/12/national-pharmaceutical-policy-2012.html
26. Sooksriwong C, Yoongthong W, Suwattanapreeda S, Chanjaruporn F. Medicine prices in Thailand: a result of no medicine pricing policy. Southern Med Review. 2009;2(2):10-4.

27. Pier EG, Lloréns MB. Trabajando por la salud de la población: propuestas de política para el sector farmacéutico. Ciudad de México: Fundación Mexicana para la Salud; 2011.

28. Department of Pharmaceuticals (IN). National pharmaceuticals pricing policy, 2012. New Deli: Department of Pharmaceuticals; 2012.

29. Souza CMA. A regulação do preço dos medicamentos genéricos no Brasil [dissertação]. Rio de Janeiro: Universidade Federal do Rio de Janeiro; 2020.

30. Medicines for Europe. Country specific market access policies 2018. Brussels: Medicines for Europe; 2018[acesso 15 set 2019]. Disponível em: https://www.medicinesforeurope. com/wp-content/uploads/2018/05/20180524-Medicines-forEurope-recommendations_V1.0.pdf

31. Brasil. Decreto № 2.181, de 20 de março de 1997. Dispõe sobre a organização do sistema nacional de defesa do consumidor, SNDC, estabelece as normas gerais de aplicação das sanções administrativas previstas na lei $\mathrm{N}^{\circ} 8.078$, de 11 de setembro de 1990, revoga o decreto № 861 , de 9 julho de 1993, e dá outras providências. Diário Oficial União. 21 mar 1997.

32. Consultor Salud. Así quedaría control de precio de medicamentos. Consultor Salud. 11 abr 2013[acesso 3 abr 2020]. Disponível em: https://consultorsalud.com/asi-qued aria-control-de-precio-de-medicamentos-2/

Contribuição dos Autores

Miranda C - Concepção, planejamento (desenho do estudo), aquisição, análise, interpretação dos dados e redação do trabalho. Paranhos J, Hasenclever L - Concepção, planejamento (desenho do estudo) e redação do trabalho. Todos os autores aprovaram a versão final do trabalho.

Conflito de Interesse

Os autores informam não haver qualquer potencial conflito de interesse com pares e instituições, políticos ou financeiros deste estudo.

Licença CC BY-NC atribuição não comercial. Com essa licença é permitido acessar, baixar (download), copiar, imprimir, compartilhar, reutilizar e distribuir os artigos, desde que para uso não comercial e com a citação da fonte, conferindo os devidos créditos de autoria e menção à Visa em Debate. Nesses casos, nenhuma permissão é necessária por parte dos autores ou dos editores. 